\title{
Towards integrated care in breastfeeding support: a cross-sectional survey of practitioners' perspectives
}

\author{
Stefanie Inge Rosin ${ }^{1 *}$ and Irena Zakarija-Grković ${ }^{2}$
}

\begin{abstract}
Background: Integrated care is defined as concerted action of healthcare providers ensuring continuity of care within a patient-centered approach, thus contributing to healthcare efficiency and quality. Apart from the WHO/UNICEF Baby-Friendly Initiatives, integrated care has been poorly explored within the context of breastfeeding support. The aim of this study was to investigate the experience of breastfeeding support practitioners, identifying barriers and facilitators towards integrated care.
\end{abstract}

Methods: A 62-item survey was conducted among 900 participants at 3 international breastfeeding conferences. Analysis included uni-and bivariate descriptive statistics, categorizing of mutually exclusive response groups and thematic networks analysis of responses to 18 open-ended items.

Results: Three-hundred-and-one participants (33\% response), from 34 predominantly industrialized countries (98\%) on nearly all continents, responded to the survey. Norwegian residents alone, felt sufficiently supported in providing breastfeeding support by other healthcare providers, the work environment, society, the media and their National Breastfeeding Committee $(P<0.05)$. Out of 11 suggested measures for effective breastfeeding promotion, $96 \%$ of respondents ranked integrated care as the most important. The largest response group identified in open-ended items, as a major barrier to integrated care in breastfeeding support, was "lacking or failing health promotion strategies" ( $n=454)$, followed by "a lack of vertically integrated care" ( $n=268)$, described mainly as unsatisfactory cooperation within healthcare. This inconsistency of care also impairs "shared decision-making" on infant feeding for parents, including accessibility of information and support $(n=265)$. Among other measures, $29 \%$ of respondents recommended incentivizing integrated breastfeeding support within healthcare. Two figures, based on open-ended response evaluations, illustrate participants' ideas of the National Breastfeeding Committees' role in coordinating policies and protagonists towards integrated breastfeeding support, and a family-centered model of integrated care to facilitate successful breastfeeding.

Conclusions: According to practitioners in breastfeeding support, integrated care is essential for successful breastfeeding. Quality and accessibility of breastfeeding support should be motivated by healthcare system incentives, to counter the reported lack of consistency of care within and beyond healthcare. To effectively integrate a continuum of breastfeeding support into healthcare and society, a policy consensus and strong political action are indispensable, with coordination by an empowered National Breastfeeding Committee.

Keywords: Integrated care, Breastfeeding support, Practitioners in breastfeeding support, Continuum of care, Consistency of care

\footnotetext{
* Correspondence: stefanie.rosin@gmx.de

${ }^{1}$ www.stillberatung-rosin.de, Berlin, Germany

Full list of author information is available at the end of the article
} 


\section{Background}

Integrated care can be described as a collaborative approach among healthcare professionals. The World Health Organization (WHO) defines integrated care as [1]:

"the management and delivery of health services so that clients receive a continuum of preventive and curative services, according to their needs over time and across different levels of the health system."

Integrated care has become increasingly important for healthcare systems to optimize continuity, consistency and quality of care, while ensuring interdisciplinary cooperation and cost-efficiency.

Integrated care requires consistency of treatment and advice from multi-professional healthcare providers, independent of setting, otherwise:

"Without integration at various levels, all aspects of health care performance suffer. Patients get lost, needed services fail to be delivered, or are delayed, quality and patient satisfaction decline, and the potential for cost-effectiveness diminishes" ([2], page 2).

Adequate education, exchange between healthcare providers and respect of different healthcare disciplines are indispensable for integrating care toward a patientcentered focus, optimizing cost-efficiency, patient satisfaction and health outcomes.

Breastfeeding rates dropped to an all-time low in the mid-20th century [3] as a result of industrialization [4] and medicalization of birth and infant feeding [5]. Today, breastfeeding rates are increasingly considered core health outcomes for maternal and child health [6-8] and infant survival $[9,10]$. Improved breastfeeding rates support cost savings in terms of disease prevention and health promotion $[10,11]$.

Establishing and sustaining a breastfeeding relationship is a vulnerable process, which has to be learned by the mother-baby-dyad [12]. Support for this relationship involves an array of health workers and services through the ante-, peri- and postnatal period. Consequently, WHO and UNICEF developed the Baby-Friendly Initiatives [13], aimed at integrating breastfeeding support into key maternity healthcare settings including hospitals [14] and the community [15]. Hospital accreditation requires following the evidence-based "Ten Steps to successful breastfeeding", representing an integrated care pathway of breastfeeding support before, during and after hospital admission. This includes, among other quality criteria, providing information to parents during pregnancy, skillfully supporting bonding and latching, avoidance of mother-baby separation and providing mother support groups and/or hotlines after hospital discharge.
Furthermore, WHO and UNICEF recommend the creation of National Breastfeeding Committees (NBCs) to protect, promote and support breastfeeding [16]. Foundations of NBCs started in the 1990s following the Innocenti Declaration, for instance in Canada, USA and Poland, later in Greece, Sweden, Switzerland, Croatia and Romania; while some are no longer active, e.g. in Romania, or have never been founded, e.g. in Japan or France ([17, 18], e-mail correspondence of the first author with governments and practitioners in breastfeeding support in January and February 2016). Their original tasks include the prevention of unethical marketing of breast-milk substitutes according to the International Code [19], the creation of breastfeedingfriendly legislation and policies, including adequate maternal leave, and the spreading of the Baby-Friendly Initiatives on a national level [13-16]. These policies are part of the "Global Strategy for Infant and Young Child Feeding" (Global Strategy), which aims to re-establish breastfeeding as the universal infant feeding norm [20].

One obstacle to achieving this goal is the documented lack of healthcare professionals trained in providing breastfeeding support [21-24]. Consequently, as a key measure in achieving Baby-Friendly standards, WHO and UNICEF mandate training for all maternity healthcare providers. To further compensate this shortage, a new cadre of dedicated practitioners in breastfeeding support has emerged, initially as volunteers including La Leche League International counsellors, who provide direct assistance to mother-baby dyads and facilitate mother-to-mother support groups [25], followed by other NGOs with the same focus [26, 27]; then as healthcare professionals, including International Board Certified Lactation Consultants (IBCLCs) [28] and physicians with a special interest in breastfeeding medicine [29]. All of these practitioners in breastfeeding support play an important role in breastfeeding initiation and sustainment, implementation of Baby-Friendly standards, increasing breastfeeding rates, and improving mothers' satisfaction with healthcare [30-32]. Midwives also perform a vital role in breastfeeding support, especially when facilitating natural childbirth and breastfeeding initiation within the first hour after birth [33, 34].

This study investigates the integrated care concept within breastfeeding support, by analyzing and describing from the perspective of practitioners, how breastfeeding support functions within the following integrated care fields, and how it can be improved [35]:

- Vertical integration defined across primary, hospital and tertiary care services

- Integration within one sector (e.g. within maternity care services)

- The use of system incentives, such as governance, guidance, funding and payment mechanisms, that seek to embed and reward integrated care 
- Implementation of health promotion strategies

- The impact of integrated care in reducing health inequalities

- Horizontal integration between health services, social services and other care providers

- Delivery systems that bring together clinicians and managers, funders and deliverers, professionals and patients.

- Integration between care providers and patients that supports shared-decision making

\section{Methods}

\section{Study design and setting}

This cross-sectional survey was conducted in 2008 at 3 major international breastfeeding conferences: European Lactation Consultants Alliance (ELACTA, formerly $\operatorname{VELB}=$ Verband Europaeischer LaktationsberaterInnen [Association of European Lactation Consultants])/International Lactation Consultant Association (ILCA) Conference, October 1-3; Academy of Breastfeeding Medicine (ABM) regional meeting, October 4-6, both in Vienna, Austria; and La Leche League Germany National Meeting (LLL), September 26-28, Dassel, Germany.

\section{Questionnaire design}

The questionnaire was created in the context of a $\mathrm{PhD}$ program undertaken in the Faculty of Health Sciences at the University of Bielefeld, Germany, using relevant literature on questionnaire design [36-39]. Feedback was provided by researchers from the Leibniz Institute for the Social Sciences "GESIS", Mannheim, Germany.

The survey consisted of 62 questions (44 closed, 18 open), covering a range of topics, including: respondent profile (11 items), work situation (29 items), contentedness (3 items), priority measures for the integration of breastfeeding support (11 items), expectations (3 items), and future prospects (5 items). A four-response Likert scale provided 2 levels of agreement or importance of the item's statement, and 2 levels of disagreement or unimportance, without a neutral response possibility. Several open questions were provided to enable respondents to elaborate upon closed question topics.

The questionnaire was first developed in German and then translated into English, to be merged into a bilingual questionnaire. It was pilot tested among a group of 12 practitioners in breastfeeding support to assess intelligibility, clarity and relevance. Subsequently, the questionnaire was shortened, clarified and re-structured. Native speakers in German and English, and public health scientists approved the final version. Internal consistency was acceptable with a Cronbach's Alpha of 0.7. The complete questionnaire is available in the dissertation annex [40].

\section{Data collection and analysis}

The survey was distributed to conference participants, who returned the completed form to a collection point at the conference venues or by postal mail. Eighteen respondents were contacted by e-mail in a second round to further clarify responses and several missing values. German open-ended responses were translated into English by the first author, who has a university degree in translation and is a German native speaker, and finally checked by an English native speaker, who is knowledgeable in the field of lactation.

To enable cross tabulations with selected characteristics, new variables with 2 categories were formed within the statistical database, to compare the chosen characteristic with the rest of the sample (e.g. the Norwegian residency was coded as 1 , all other residence countries were coded as 2). Thus outcomes were cross tabulated using chi-square tests and exact Fisher tests by age quartiles, profession, residence (for the top 12 represented countries), type of conference attended, voluntary or paid breastfeeding support, quantity of breastfeeding support provided, estimate of compensation, acknowledgement on the job, and degree of personal experience with breastfeeding. Statistically significant associations were set at a level of $P<0.05$, based on a four-response Likert scale. Statistical analysis was carried out using SPSS software (version 17, Chicago, IL, 2008).

To further explore the importance respondents ascribed to "integrated care" for effective breastfeeding support, we evaluated open-ended responses using qualitative methods. Practitioners in breastfeeding support provided free-text responses to most open-ended items, with responses ranging from a few words to complete sentences. These free-text responses were read multiple times and discussed within the research team to elicit their integrated care relevance and be sorted into integrated care categories, using a deductive approach. Categorization followed the above mentioned integrated care fields. Thus mutually exclusive categories were developed and quantified in groups and sub-groups, using Excel computer software [41]. Where useful, direct quotes are presented to illustrate the categorizations.

Since we merged two complex topics "integrated care" and "breastfeeding support", we aimed at presenting this complexity in an understandable way. Therefore we further applied thematic networks analysis, which allowed a rich description of the large data set of open-ended responses at different organizational levels [42]. We indexed respondents' statements into categories using an inductive approach, thus establishing a framework of thematic ideas of basic, organizing and global themes. This process included several rounds of discussion, reviews and revisions within the team, finally reaching consensus. To optimize comprehensibility of 
the complex systemizations detected, results of thematic networks analysis are presented diagramatically.

\section{Ethical approval}

All organizations involved gave permission for the study. Participants were informed that the questionnaire was to be used for a dissertation study in public health and that participation was voluntary and anonymous, with the option of providing contact details. A completed and returned questionnaire was interpreted as an indication of consent. Ethical approval for the dissertation study was obtained from the ethical committee of Bielefeld University (No. \#2013-001), where the study was conducted within a $\mathrm{PhD}$ program in health sciences.

\section{Results}

\section{Participants}

Of the 900 questionnaires distributed 301 were returned, representing a response of $33 \%$. The majority were VELB/ILCA conference participants (77 \%), $15 \%$ were from LLL Germany and $8 \%$ from the ABM conference. Respondents came from almost every continent and thus represented an international sample, with the exception of South America. There was a clear prevalence of participants from industrialized countries (98\%). Respondents were between 21 and 78 years old and included 3 male participants. Eighty-five percent of respondents claimed to have personal breastfeeding experience $(n=256)$, with $72 \%$ of those over one year per child $(n=183)$. Ninety percent of survey respondents had a qualification in breastfeeding counselling $(n=272)$, with the ratio of unpaid to paid practitioners in breastfeeding support being roughly 1:3 (Table 1 ).

Table 1 Characteristics of respondents $(n=301)$

\begin{tabular}{ll}
\hline Characteristic & $n(\%)$ \\
\hline Continent of residence & $244(81)$ \\
Europe & $28(9.3)$ \\
North America & $18(6.0)$ \\
Oceania & $9(3.0)$ \\
Asia & $2(0.7)$ \\
Africa & \\
Top twelve represented countries & $107(35.5)$ \\
Germany & $44(14.6)$ \\
Austria & $26(8.6)$ \\
Switzerland & $21(7.0)$ \\
USA & $16(5.3)$ \\
Australia & $15(5.0)$ \\
Netherlands & $8(2.7)$ \\
Italy & $7(2.3)$ \\
Canada & $6(2.0)$ \\
Belgium &
\end{tabular}

Table 1 Characteristics of respondents ( $n=301)$ (Continued)

\begin{tabular}{|c|c|}
\hline Luxembourg & $4(1.3)$ \\
\hline Norway & $4(1.3)$ \\
\hline Sweden & $4(1.3)$ \\
\hline \multicolumn{2}{|l|}{ Profession ${ }^{a}$} \\
\hline Nurse & $146(48.5)$ \\
\hline Pediatric & $52(17.3)$ \\
\hline Maternity & $47(15.6)$ \\
\hline Lactation Consultant & $26(8.6)$ \\
\hline General & $21(7.0)$ \\
\hline Midwife & $53(17.6)$ \\
\hline Certified Doula & $1(0.3)$ \\
\hline Physician & $44(14.6)$ \\
\hline Pediatrician & $25(8.3)$ \\
\hline Gynecologist & $11(3.6)$ \\
\hline General Practitioner & $9(3.0)$ \\
\hline Researcher (field of research as stated by respondents) & $19(6.3)$ \\
\hline Medical & $7(2.3)$ \\
\hline Public health & $7(2.3)$ \\
\hline Others $^{\mathrm{b}}$ & $5(1.7)$ \\
\hline Public health official & $39(13.0)$ \\
\hline Trainer of health care providers & $16(5.3)$ \\
\hline Social and health service provider & $10(3.3)$ \\
\hline Infant nutritionist & $7(2.3)$ \\
\hline Baby-Friendly Hospital Initiative coordinator & $2(0.7)$ \\
\hline Others $^{c}$ & $7(2.3)$ \\
\hline Health policy maker & $8(2.6)$ \\
\hline Advocator for breastfeeding & $3(1.0)$ \\
\hline Government advisor & $2(0.7)$ \\
\hline Others $^{d}$ & $3(1.0)$ \\
\hline Professions outside the health care sector ${ }^{e}$ & $28(9.3)$ \\
\hline Breastfeeding support qualifications ${ }^{f}$ & 327 \\
\hline International Board Certified Lactation Consultant & $227(75.4)$ \\
\hline Voluntary ${ }^{9}$ & $73(24.3)$ \\
\hline Other $^{\mathrm{h}}$ & $27(9)$ \\
\hline \multicolumn{2}{|l|}{ Payment for breastfeeding support } \\
\hline Unpaid & $66(22)$ \\
\hline Unpaid and paid & $23(7.6)$ \\
\hline Paid & $194(64.5)$ \\
\hline
\end{tabular}

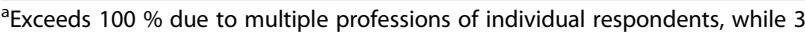
respondents reported no qualification

${ }^{\mathrm{b}}$ Natural sciences, Psychology, Political Sciences, Social Sciences, Epidemiology 'National Breastfeeding Committee member, nutritionist, supporter of health care providers, prevention activist

${ }^{\mathrm{C} L o c a l}$ public health department, Health Ministry, National and international policies 'Teacher, psychologist, administrator, bank clerk, parents' counsellor, bookseller, lecturer, translator, TV journalist, student, optician, dental hygienist, consultant for medical products, physiotherapist, speech therapist, bio-medical analyst 'Exceeds $100 \%$ due to multiple qualifications: IBCLC + LLL $7.6 \%(n=23)$, $\mathrm{IBCLC}+\mathrm{AFS} 1 \%(n=3), \mathrm{IBCLC}+\mathrm{ABA} 1 \%(n=3)$

${ }^{9}$ La Leche League $21 \%(n=64)$, Arbeitsgemeinschaft Freier Stillgruppen $2 \%$ $(n=6)$, Australian Breastfeeding Association $1 \%(n=3)$

${ }^{h}$ Health care providers $8 \%(n=24)$, Breastfeeding mothers $7 \%(n=2)$, WHO

$40 \mathrm{~h}$ course qualification $0.3 \%(n=1)$ 
There were only a few significant differences by sociodemographic characteristics between response groups; these differences are reported in the results section, where relevant. Overall the response pattern within the quantitative items was predominantly homogenous, indicating extensive consensus among our international and interdisciplinary sample.

\section{Integrated care in breastfeeding support}

Overall, respondents lamented a lack of consistency and continuity of breastfeeding support, stating that their service was insufficiently supported. Only Norwegian residents felt sufficiently supported in providing breastfeeding support by other healthcare providers $(p=0.01)$, the work environment $(P=0.01)$, society $(p=0.009)$, the media $(p=$ $0.005)$ and their National Breastfeeding Committee, due to their successful promotion of breastfeeding $(p=0.000)$. Consequently, when ranking 11 measures for breastfeeding promotion, respondents chose "integrated care" as the most important (Table 2). Based on the relevant integrated care fields listed in the background section, Table 3 presents an overview of the barriers to integrated care in breastfeeding support including quantifications, using deductive evaluations of open-ended responses. Further details on the largest response groups "vertically integrated care" and "health promotion strategies" can be found in Additional files 1 and 2.

\section{Vertically integrated care}

Vertically integrated care refers to optimal collaboration between providers at different levels, such as primary, secondary and tertiary care.
Eighty-nine percent of respondents reported a failure of vertical cooperation in their work environments, attributing this to a lack of knowledge and skill in providing breastfeeding support among healthcare providers, especially physicians (Table 3). Support and acknowledgement by other healthcare professionals, including superiors, was also described as poor with only $7.6 \%$ of respondents reporting a supportive work environment. Additional file 1 shows in detail the barriers against vertically integrated breastfeeding support, described in open-ended responses from the perspective of practitioners in breastfeeding support. This includes interesting aspects and quotations mentioned within response groups, while each quotation goes with the respondent's residence country, the profession and qualification in breastfeeding support.

When asked how important the education of healthcare professionals in breastfeeding support to IBCLC standard was, this measure was considered as very important/important by $90 \%$ (Table 2), with almost all participants agreeing that the IBCLC credential should become the standard for all healthcare providers in maternity care to facilitate vertically integrated breastfeeding support. Several respondents suggested that healthcare professionals other than maternity care providers should be enabled to provide basic support for breastfeeding, while all healthcare providers should become aware of lactation consulting possibilities, including timely referrals to lactation consultants (12.9\%; $n=$ 39). Ninety-four percent of nurses/midwives $(n=187)$, $88 \%$ of physicians $(n=39)$ and $92 \%$ of other professionals $(n=53)$ thought that those working with

Table 2 Priority ranking of eleven suggested measures for effective breastfeeding promotion

\begin{tabular}{|c|c|c|c|c|c|}
\hline \multicolumn{2}{|c|}{ Univariate statistical evaluations } & \multicolumn{4}{|c|}{ 4-point Likert scale } \\
\hline Mean score & Measure for breastfeeding promotion & $\begin{array}{l}\text { very } \\
\text { important } \\
\left(4^{a}\right) \\
n / \%\end{array}$ & $\begin{array}{l}\text { important } \\
\left(3^{a}\right) \\
n / \%\end{array}$ & $\begin{array}{l}\text { less } \\
\text { important }^{b} \\
\left(2^{a}\right) \\
n / \%\end{array}$ & $\begin{array}{l}\text { not at all } \\
\text { important }^{b} \\
\left(1^{a}\right) \\
n / \%\end{array}$ \\
\hline 3.87 & Integrated care within breastfeeding support & $256 / 85.0$ & $34 / 11.3$ & $1 / 0.3$ & $1 / 0.3$ \\
\hline 3.86 & Promotion of breastfeeding integrated into health policies & $252 / 83.7$ & $37 / 12.3$ & $2 / 0.7$ & - \\
\hline 3.75 & Education of the public on benefits of breastfeeding and risks of substitutes & $225 / 74.8$ & $57 / 18.9$ & $9 / 3.0$ & - \\
\hline 3.74 & Promotion of research independent of commercial sponsoring & $219 / 72.8$ & $64 / 21.3$ & $5 / 1.7$ & - \\
\hline 3.73 & Media campaigns for breastfeeding & $219 / 72.8$ & $61 / 20.3$ & 9/3.0 & - \\
\hline 3.70 & $\begin{array}{l}\text { Implementation of the International Code of Marketing of Breast-milk } \\
\text { Substitutes into legislation }\end{array}$ & $220 / 73.1$ & $56 / 18.6$ & $9 / 3.0$ & $4 / 1.3$ \\
\hline 3.61 & Implementation of Baby-Friendly standards as the norm & $201 / 66.8$ & $65 / 21.6$ & $22 / 7.3$ & $1 / 0.3$ \\
\hline 3.59 & Upgrade the profession lactation consultant to create career possibilities & $188 / 62.5$ & $83 / 27.6$ & $18 / 6.0$ & - \\
\hline 3.58 & Implement the IBCLC credential as educational standard within healthcare & $193 / 64.1$ & $78 / 25.9$ & $17 / 5.6$ & $3 / 1.0$ \\
\hline 3.57 & Governmental monitoring of and penalty for Code violations & $180 / 59.8$ & $91 / 30.2$ & $9 / 3.0$ & $4 / 1.3$ \\
\hline 3.38 & Development of a human milk bank network & $133 / 44.2$ & $110 / 36.5$ & $25 / 8.3$ & $3 / 1.0$ \\
\hline
\end{tabular}

${ }^{a}$ Statistical value for SPSS evaluations

${ }^{b}$ Conspicuous minority was addressed in a second question round, and their arguments were discussed 
Table 3 Barriers to integrated care in breastfeeding support, according to integrated care fields

\begin{tabular}{|c|c|c|c|c|c|c|c|}
\hline \multicolumn{5}{|c|}{ Integrated care response groups according to categorization of open-ended responses ( $\mathrm{n}$ ) } & \multicolumn{3}{|l|}{ Total $n=1,168$} \\
\hline \multirow{2}{*}{$\begin{array}{l}\text { Vertical integration }{ }^{\text {a }} \text { (268) } \\
\text { Lack of concerted action } \\
\text { within healthcare to } \\
\text { cooperate towards } \\
\text { integrated care in } \\
\text { breastfeeding support (88) }\end{array}$} & \multirow{2}{*}{$\begin{array}{l}\text { Within one sector (52) } \\
\text { Lacking implementation } \\
\text { of Baby-Friendly } \\
\text { standards (26) }\end{array}$} & \multirow{2}{*}{$\begin{array}{l}\text { Incentives (87) } \\
\text { Lacking incentives } \\
\text { of health insurance } \\
\text { companies to motivate } \\
\text { breastfeeding as disease } \\
\text { prevention (35) }\end{array}$} & \multicolumn{2}{|c|}{ Health promotion strategies ${ }^{b}(454)$} & \multirow{2}{*}{$\begin{array}{l}\text { Health inequalities (19) } \\
\text { Differing breastfeeding } \\
\text { rates among social } \\
\text { classes contribute to } \\
\text { exacerbate health } \\
\text { inequalities (11) }\end{array}$} & \multirow{2}{*}{$\begin{array}{l}\text { Horizontal integration } \\
\text { (23) }\end{array}$} & \multirow{2}{*}{$\begin{array}{l}\text { Shared decision- } \\
\text { making (265) } \\
\text { Lack of visible } \\
\text { marketing strategies } \\
\text { for breastfeeding to } \\
\text { counter formula } \\
\text { marketing (93) }\end{array}$} \\
\hline & & & $\begin{array}{l}\text { Lacking policies and } \\
\text { their implementation } \\
\text { to protect, promote } \\
\text { and support } \\
\text { breastfeeding (127) }\end{array}$ & $\begin{array}{l}\text { Lacking research } \\
\text { on policy } \\
\text { implementation (26) }\end{array}$ & & & \\
\hline $\begin{array}{l}\text { Lack of healthcare } \\
\text { providers competent } \\
\text { in breastfeeding support, } \\
\text { lacking recognition of } \\
\text { expertise within healthcare (64) }\end{array}$ & $\begin{array}{l}\text { Lacking quality of } \\
\text { breastfeeding support } \\
\text { within hospitals (14) }\end{array}$ & $\begin{array}{l}\text { Lack of healthcare } \\
\text { system incentives } \\
\text { to prevent } \\
\text { unnecessary } \\
\text { supplementation } \\
\text { and interventions } \\
\text { at birth (24) }\end{array}$ & $\begin{array}{l}\text { Lacking impact of } \\
\text { NBCs on policies and } \\
\text { lacking coordination } \\
\text { of policies and } \\
\text { protagonists (76) }\end{array}$ & $\begin{array}{l}\text { Lacking promotion } \\
\text { of breastfeeding as a } \\
\text { preventive measure (25) }\end{array}$ & $\begin{array}{l}\text { Lacking access to } \\
\text { adequate breastfeeding } \\
\text { support, independent } \\
\text { of socioeconomic } \\
\text { factors (4) }\end{array}$ & $\begin{array}{l}\text { Lacking competence } \\
\text { of school teachers } \\
\text { in the field of } \\
\text { breastfeeding (5) }\end{array}$ & $\begin{array}{l}\text { Lacking perception } \\
\text { of breastfeeding as } \\
\text { the norm, and } \\
\text { lacking breastfeeding- } \\
\text { friendliness in } \\
\text { society (57) }\end{array}$ \\
\hline $\begin{array}{l}\text { Lack of physicians' } \\
\text { cooperation towards } \\
\text { integrated care in } \\
\text { breastfeeding support (49) }\end{array}$ & $\begin{array}{l}\text { Lacking integration of } \\
\text { adequate breastfeeding } \\
\text { support into routine } \\
\text { hospital care (12) }\end{array}$ & $\begin{array}{l}\text { Lack of adequate } \\
\text { compensation from } \\
\text { health insurance } \\
\text { companies for } \\
\text { receiving and } \\
\text { providing } \\
\text { breastfeeding } \\
\text { support (16) }\end{array}$ & $\begin{array}{l}\text { Lack of high-quality } \\
\text { and ethically sound } \\
\text { research and its } \\
\text { funding, independent } \\
\text { of commercial } \\
\text { interests (68) }\end{array}$ & $\begin{array}{l}\text { Lacking foundation } \\
\text { of } \mathrm{NBCS} \mathbf{c} \mathbf{d} \text { as Delivery } \\
\text { Systems in several } \\
\text { countries (20) }\end{array}$ & $\begin{array}{l}\text { Lacking access to } \\
\text { breastfeeding support } \\
\text { impairs patient } \\
\text { satisfaction with } \\
\text { healthcare (4) }\end{array}$ & $\begin{array}{l}\text { Lack of family } \\
\text { counselling services } \\
\text { with competence } \\
\text { in breastfeeding } \\
\text { support (5) }\end{array}$ & $\begin{array}{l}\text { Lack of consistent } \\
\text { information on } \\
\text { breastfeeding by } \\
\text { healthcare } \\
\text { professionals ( } 35 \text { ) }\end{array}$ \\
\hline $\begin{array}{l}\text { Lack of researchers' } \\
\text { knowledge on } \\
\text { breastfeeding, lack of } \\
\text { practice-oriented } \\
\text { research to improve } \\
\text { breastfeeding support (34) }\end{array}$ & & $\begin{array}{l}\text { Lacking incentives } \\
\text { for parents for } \\
\text { breastfeeding and } \\
\text { the donation of } \\
\text { human milk (12) }\end{array}$ & $\begin{array}{l}\text { Lacking support } \\
\text { and funding } \\
\text { for breastfeeding } \\
\text { promotion from } \\
\text { governments, health } \\
\text { insurance companies, } \\
\text { politicians (42) }\end{array}$ & $\begin{array}{l}\text { Lacking legislation to } \\
\text { protect and promote } \\
\text { breastfeeding, } \\
\text { including adequate } \\
\text { maternal leave (20) }\end{array}$ & & & $\begin{array}{l}\text { Lacking dissemination } \\
\text { of relevant research } \\
\text { to practitioners and } \\
\text { the public (35) }\end{array}$ \\
\hline $\begin{array}{l}\text { Lack of cooperation } \\
\text { between voluntary and } \\
\text { professional practitioners (19) }\end{array}$ & & & $\begin{array}{l}\text { Lacking } \\
\text { implementation } \\
\text { and monitoring of } \\
\text { the } \operatorname{Code}^{\mathbf{d}}(36)\end{array}$ & $\begin{array}{l}\text { Lack of health policies } \\
\text { facilitating a patient- } \\
\text { centered approach in } \\
\text { providing breastfeeding } \\
\text { support (8) }\end{array}$ & & & $\begin{array}{l}\text { Lacking information } \\
\text { and education of } \\
\text { the public, including } \\
\text { prenatal courses (34) }\end{array}$ \\
\hline $\begin{array}{l}\text { Lack of human milk } \\
\text { bank networks to facilitate } \\
\text { integrated care in } \\
\text { breastfeeding support (14) }\end{array}$ & & & & $\begin{array}{l}\text { Lack of prioritizing } \\
\text { breastfeeding protection } \\
\text { and promotion towards } \\
\text { "health before profit" (8) }\end{array}$ & & & $\begin{array}{l}\text { Lacking control of } \\
\text { sponsored media } \\
\text { portrayal of infant } \\
\text { feeding (11) }\end{array}$ \\
\hline
\end{tabular}

a More details of the "Vertical Integration" category can be found in Additional file 1

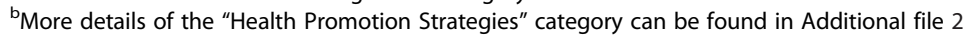

"More details of the "Delivery System" category can be found in Fig. 1

"See "Abbreviations" following the main manuscript 
breastfeeding families should be trained as IBCLCs. However, the IBCLC qualification was considered important by only $50 \%$ of residents from Norway ( $p=$ $0.03)$, Sweden $(p=0.02)$, Belgium $(p=0.03)$ and Canada $(p=0.02)$.

Respondents called for the integration of voluntary and professional breastfeeding support services and improved collaboration between them ( $6 \%$ / Additional file 1), with one respondent requiring:

"Easy access to mother support groups"

(Netherlands/General Practitioner/Healthcare Provider)

Additionally, respondents considered the extension of a human milk bank network as an important resource for providing human milk to infants in need through the cooperation of different care levels (80.7\%; $n=243$; Table 2).

\section{Integrated care within one sector}

The setting of interest for this sector is the maternity hospital. Integration of care in this setting was considered possible if hospitals were to achieve Baby-Friendly designation, which was considered very important/important by $88 \%$ (Table 2). Those who considered it as less important $(7.6 \% / n=23)$ stated that it was not achievable in their setting, or cited the misuse of the title with no real fulfillment of the standards, especially in Romania and USA. Only $3 \%$ of lactation professionals $(n=10)$ explicitly reported a supportive work environment in the hospital setting.

Seventeen percent of participants described difficulty implementing evidence-based breastfeeding support into hospital care (Table 3), including slow progress and frequent backlash. Important aspects mentioned within this category are the lack of remuneration and acknowledgement for their work in this setting, lack of time for lactation consulting, lack of staff and breastfeeding clinics for integrated care within this setting and after hospital discharge, adverse routines such as the routine supplementation with infant formula,the separation of mothers and infants, and the failure of collaboration with non-educated healthcare staff with non-supportive attitudes. Two participants wrote:

"Currently the development on my ward towards improved breastfeeding support is stagnating" (Luxembourg/Pediatric Nurse at Maternity Ward/ IBCLC)“

"The routines in my hospital prevent the application of my knowledge and skills as a lactation consultant."

(Germany/Midwife/IBCLC)

\section{Incentives for breastfeeding support within the healthcare system}

Incentives are defined as governance, guidance, funding and payment mechanisms that seek to embed and reward integrated care. Twenty-nine percent of respondents called for the integration of breastfeeding support into health services by establishing system incentives (Table 3).

Within the "incentives" category, several respondents advocated for the recognition of midwifery and breastfeeding support as essential healthcare, complaining about non-supportive and counter-productive structures in the current healthcare systems both for lactation professionals and midwives, thus impairing natural birth and breastfeeding (5\%). Two respondents wrote:

"Abolish financial incentives for birth interventions and the use of formula, such as formerly within the US Women, Infant and Children Program..."

(USA/Maternity Nurse/IBCLC)

\section{"Provide regular remuneration from health insurance companies for breastfeeding support" \\ (Poland/General Practitioner/IBCLC)}

Four percent of participants suggested offering parents incentives for successful initiation and sustainment of breastfeeding, such as free lactation consulting services, equal access to breastfeeding support and remuneration for the donation of human milk. Ten percent of respondents defined the establishment of incentives for natural birth and breastfeeding, both for families and for the healthcare system, as a key role of health insurance companies (Table 3). They should acknowledge breastfeeding as a preventive measure deserving of financial incentives and adequate remuneration (7\%). Furthermore, health insurance companies should play an active role in the prevention of unnecessary interventions at childbirth and unnecessary supplementing with infant formula (3\%). Several respondents suggested that the National Breastfeeding Committee should lobby for this to occur (see section "delivery system"). One respondent wrote:

"There will be no increase in breastfeeding rates in the near future, as long as the current trend of obstetric interventions during childbirth continues."

(Austria/Maternity Nurse/IBCLC)

\section{Health promotion strategies towards integrated care within breastfeeding support}

Out of 11 measures, $96 \%$ of participants ranked breastfeeding promotion integrated into national health policy second in order of importance (Table 2). One open-ended question directly asked expectations of 
respondents from health policies. However, responses in the "health promotion strategies" category exceeded the sample size $(n=301)$, since remarks on health policies were provided in several items throughout the questionnaire $(n=454)$. This high response confirms the major importance given by practitioners in breastfeeding support to policies that support breastfeeding (Additional file 2). While slightly less than half of the respondents stated national policies promoting breastfeeding exist in their country of residence ( $46.6 \%$ versus $53.4 \%$ with no policies), only a quarter qualified their implementation as successful (25.1\% versus $74.9 \%$ unsuccessful). Hence, several respondents suggested that breastfeeding protection and promotion should become a priority in health policies, prioritizing "health before profit" (Additional file 2), while one complained about

"the slow and unsupported progress of a breastfeeding culture"

(Australia/Midwife/IBCLC).

Implementation of the International Code of Marketing of Breast-milk Substitutes into legislation was considered as an important measure by $91.7 \%$ of respondents (Table 2). Four percent of respondents considered this measure less important and justified this by wishing for less governmental regulations in general; an assumption that producers of breast milk substitutes will always find loopholes to get around laws and fearing that restriction of advertising might be seen as limiting freedom of expression. Ninety percent of respondents considered monitoring of, and penalty for violations of the Code very important or important, while $4 \%$ considered it less or not at all important (Table 2). Reasons for considering this measure less important were a belief that it is not practicable or feasible to control the food industry and that governments have acted as major formula buyers in the past, e.g. in the US Women, Infant and Children program, which would be hard to overcome.

\section{Health inequalities in providing breastfeeding support}

Six percent of respondents expressed concern for inequalities in healthcare because of the lack of access to breastfeeding support for families of lower socioeconomic status (Table 3). One feared that

"the gap between well-educated families of higher socioeconomic status with higher breastfeeding rates, and lower breastfeeding rates of disadvantaged families, will worsen in the future"

(Germany/Bank clerk/LLL).

In this category, respondents called "the increasing rate of teenage mothers problematic" (USA/Maternity Nurse/IBCLC);

while several respondents feared that a two-class society will develop, mentioning

\section{"the challenge to support the vulnerable" \\ (Croatia/General practitioner/IBCLC).}

Consequently, several respondents requested equal access to breastfeeding support for all families (Table 3) to be enforced by health policies (Additional file 2). Two respondents wrote:

\section{"Integrate lactation consulting into the national healthcare system" \\ (China/Obstetrician-Gynecologist/IBCLC + LLL)}

and guarantee

"lactation consulting for everyone"

(Germany/Pediatric nurse/IBCLC).

\section{Horizontally integrated care}

Horizontally integrated care is defined as care between health services, social services and other care providers. Seven percent of respondents emphasized the importance of horizontal cooperation with and between education providers, including school teachers, kindergarten teachers, day care nurses, social workers and psychologists, who should be educated in breastfeeding support (Table 3). They advocated for the education of children starting at kindergarten with the aim of normalizing breastfeeding e.g. by portraying it in children's books (5\%). In addition, several respondents suggested a network of family counselling centers that offer breastfeeding support (1.7\%/Table 3), with 3 respondents suggesting:

\footnotetext{
"The Lactational Amenorrhea Method should be included in family planning counseling"

(USA/Pediatrician, Preventive Medicine, Epidemiology, Maternal and Child Health, State and National and International Health Policies/FABM + IBCLC + LLL)
}

Teach breastfeeding as normal from kindergarten age" (USA/Lactation Consultant/IBCLC + LLL)

"Educate the importance of breastfeeding at school" (Japan/Pediatrician/IBCLC) 
Delivery system for integrated care in breastfeeding support A delivery system for integrated care should bring together clinicians and managers, funders and providers, professionals and patients. Respondents felt that the National Breastfeeding Committee bears the responsibility for such integration as part of its tasks to protect, promote and support breastfeeding $(75.4 \% / n=227)$. Eightyone percent of respondents were resident in countries with an established NBC in 2008, including nearly all of the top twelve represented countries (Table 1), with the exception of Australia and The Netherlands. The remaining $19 \%$ of respondents had no NBC established in their residence countries by 2008, including China, UAE, Japan, Lithuania, Bosnia-Herzegovina, Spain and others $([18,19]$, e-mail correspondence of the first author with practitioners in breastfeeding support in 2016). Respondents were ambivalent in their assessment regarding whether their National Breastfeeding Committee was promoting breastfeeding successfully (52.3\% successful versus. $47.7 \%$ unsuccessful), with the exception of Norwegian respondents, who assessed the performance of their "National Advisory Unit" as successful, compared to all other respondents $(P=0.000)$. When asked about their expectations of the Committee, participants expected it to play a key role in re-establishing a breastfeeding culture and to act as a major contact point for all practitioners, researchers, policy makers and parents.

The comprehensive tasks of the National Breastfeeding Committee, as identified by respondents, are shown in Fig. 1. The figure reflects practitioners' expectations

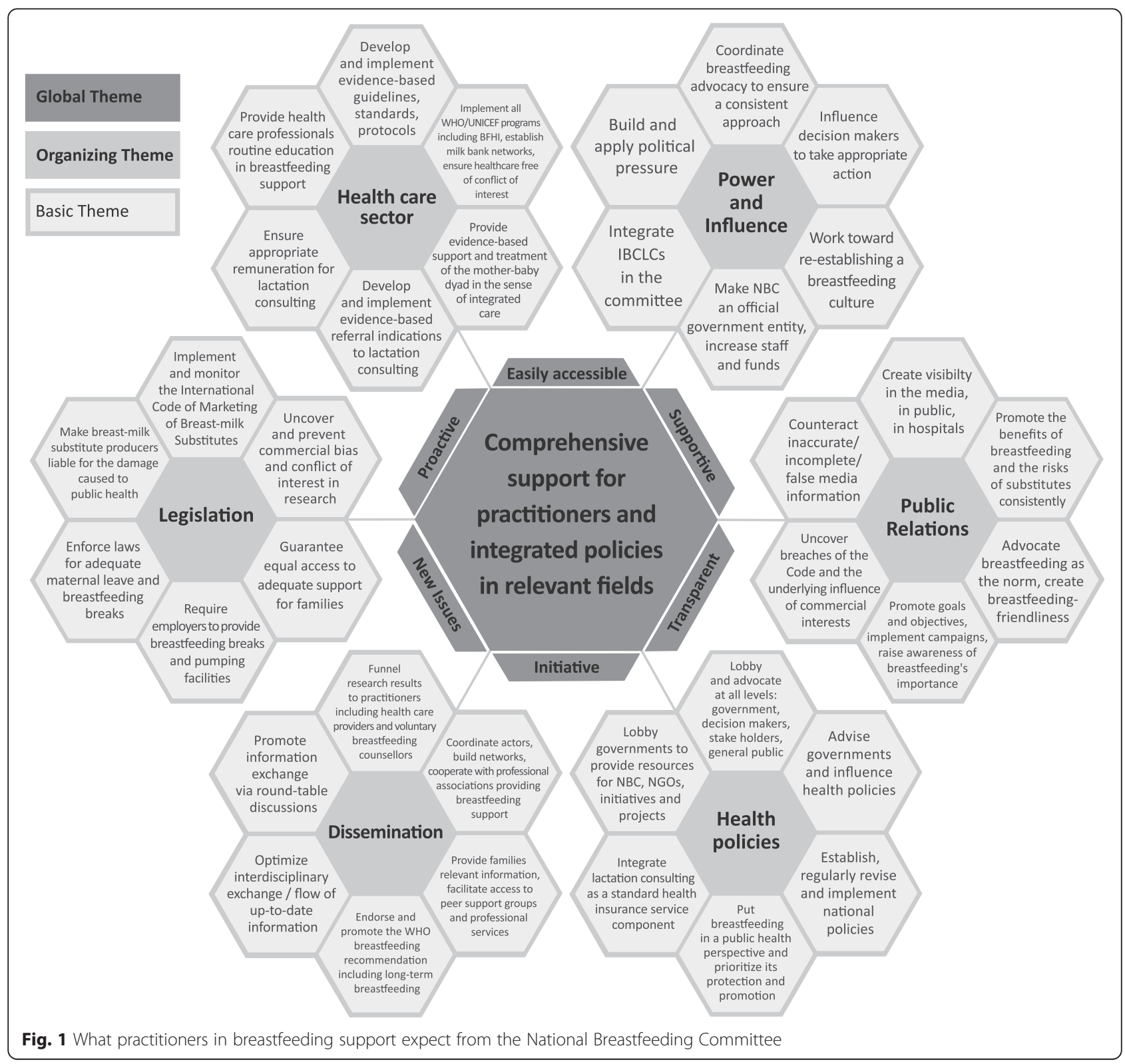


from the National Breastfeeding Committee, regardless of whether an NBC was already established in their residence countries or not, with both groups showing equal response rates of about $55 \%$. Keywords provided by respondents were first analyzed into the global theme, which is shown in the center of Fig. 1, together with desired attributes of the NBC. The organizing themes are the fields of action practitioners expect the NBC to take, while basic themes show details of the desired activities. After having identified the themes, we refined the wording of Fig. 1's keywords, with the aim of optimally representing the many important tasks described by respondents. To successfully fulfill the defined major tasks, several respondents recognized the need to provide the National Breastfeeding Committee with adequate funds, staff and authority, while some lamented that a National Breastfeeding Committee was not yet founded in their countries (e.g. Australia, France, Israel, Netherlands), with one respondent stating:

"We have a new Committee of Breastfeeding in Finland, I'm sure something will happen..."

(Finland/Public Health Nurse, Head Nurse/Healthcare Provider)

In reply to the open-ended question, what they expect from the NBC, two respondents having no NBC in their residence country wrote:

"A strong policy that is supported by appropriate legislation to give adequate maternity leave and breastfeeding breaks."

(UAE/Midwife/IBCLC)

"NBC should advise government on legislation to support breastfeeding."

(UK/Midwife/IBCLC)

Two respondents having an NBC in their residence country wrote:

"The NBC should plan and coordinate a national policy to be implemented with political support"

(Italy/Pediatrician/Healthcare Provider)

"What can I expect from a committee without funds, power and influence?"

(Germany/Midwife/IBCLC)

Respondents considered the original tasks of the NBC, as defined in 1990 [16], to be entirely relevant today (Fig. 1). Additionally, several respondents suggested the planning and conducting of a marketing strategy to convey a positive message on breastfeeding for increased public support, with the goal of making society more breastfeeding-friendly. Ninety-three percent of respondents considered advertising campaigns as very important or important (Table 2). Two respondents wrote:

\section{"Progress is only possible with broad campaigns and large investments." \\ (Germany/Pediatric Nurse/IBCLC)}

"Create an image of breastfeeding as smart, cool and career-right."

(Norway/Gynecologist, Government Advisor/

Healthcare Provider)

\section{Decision making on infant feeding}

Eighty-eight percent of respondents reported manifold obstacles on different societal levels for parents in making a shared decision on infant feeding (Table 3). The main obstacle was considered to be inconsistent, incorrect, outdated and non-evidence-based information provided by healthcare professionals to families, making parents insecure and undermining breastfeeding success, while two respondents lamented:

\section{"Breastfeeding myths from healthcare providers and aged people"}

(Taiwan R.O.C./Obstetrician,Gynecologist/IBCLC + LLL)

"Too many different opinions"

(Switzerland/Nurse/IBCLC)

Within this category, several respondents called for consistent, evidence-based, up-to-date and unequivocal information on infant feeding to facilitate breastfeeding and empower the family, with one respondent suggesting:

"Antenatal classes which include family members (father, aunts, grandparents)"

(New Zealand/Maternity Nurse/IBCLC)

In this context, several respondents requested a clear commitment by governments to the WHO public health recommendation of exclusive breastfeeding for the first 6 months and continued breastfeeding beyond 1 year of age. Twelve percent of respondents also highlighted the lack of dissemination of relevant research to back up practitioners and families, and thus provide the public with up-to-date and evidencebased facts. Eleven percent called for independent research, free from commercial interests to avoid commercial bias (Table 3). Ninety-four percent considered the promotion of independent research as a very important/important task (Table 2). 
While $52 \%$ of practitioners in breastfeeding support considered the media as non-supportive, $4 \%$ further explained in open-ended responses that parents are influenced by negative media reports harming the image of breastfeeding in society, providing incorrect information and aggressively marketing breast-milk substitutes. One respondent wrote:

\section{"Ads of breast milk substitutes are rampant on mass media"}

(South Korea/Pediatrician/Healthcare provider)

To promote shared decision-making on infant feeding unbiased by commercial interests, several respondents suggested that the National Breastfeeding Committee should counteract incorrect statements in the media and thus counter the continued attempt of the formula industry to establish bottle-feeding as the norm for infant feeding (Fig. 1). While $47 \%$ of respondents lamented lacking societal support in general, $11 \%$ further explained this shortcoming in openended responses, mentioning that the parents' social environment often provides incorrect information on infant feeding. This resulted in parents being subject to many different opinions including breastfeeding myths, making them feel insecure and impairing breastfeeding success. One respondent wrote:
"There is a cultural and educational ignorance of the natural breast function."

(USA/Maternity Nurse/IBCLC)

In this context, the education of the public about the benefits of breastfeeding and risks of substitutes scored $94 \%$ "important" versus 3 \% "less important" (Table 2). One respondent who considered this measure as less important justified this by stating that:

\section{"Without consistent breastfeeding support from} healthcare providers, the promotion of breastfeeding might be understood as a moral sermon that cannot be put into practice; therefore the education of healthcare professionals should be considered the first priority before the education of the public."

(Germany/Gynecologist/IBCLC)

While the results of this study so far have focused on identifying barriers to integrated care in breastfeeding support, and strategies to overcome those deficits, Fig. 2 shows the patients' perspective. This family-centered model is derived from all the survey results and abstracts them in the integrated care fields by filtering only the ideal outcomes of the suggested measures in terms of integrated care. These are reflected in a few keywords, relevant from a family perspective, thus

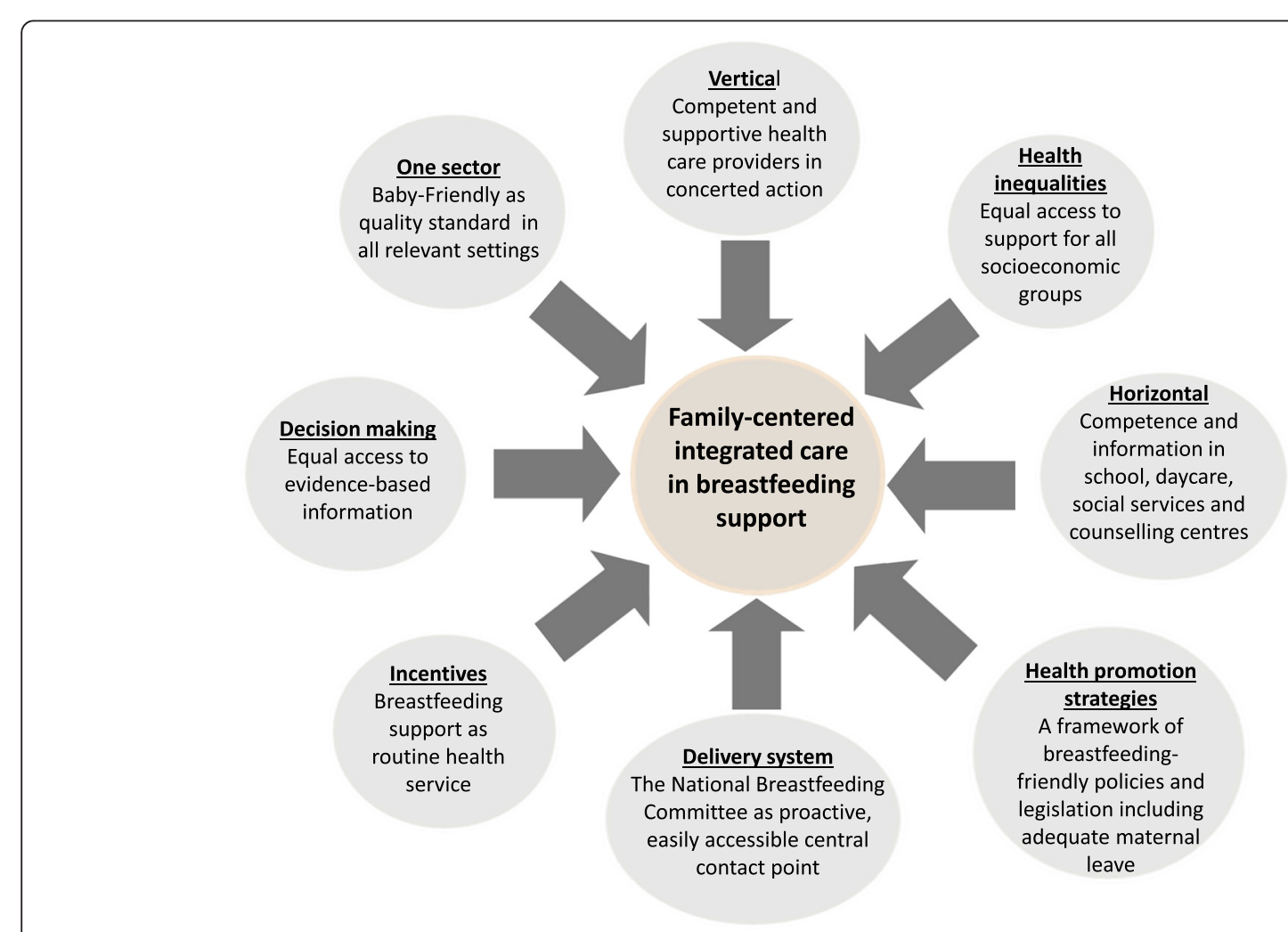

Fig. 2 A family-centered model of integrated care in breastfeeding support 
omitting all the necessary measures "behind the scenes" in terms of policies and re-structuring of healthcare. Figure 2 aims to show the whole picture of an implemented framework of integrated care in breastfeeding support as a model of a patient-centered approach to facilitate successful breastfeeding.

\section{Discussion}

\section{Integrated care within breastfeeding support}

The importance of integrated care within breastfeeding support has not been extensively studied, with the exception of the Baby Friendly Initiative [43]. Yet, interventions including some form of collaboration among sectors or different types of health professionals or health professionals and volunteers often resulted in positive outcomes in terms of breastfeeding rates [30, 31, 44, 45] and significantly greater maternal satisfaction [32, 46], as recently described in the 2016 Lancet Breastfeeding Series.

Study participants considered the WHO/UNICEF Baby-Friendly Initiative important for setting and upholding quality standards for integrated breastfeeding support in key healthcare settings. In addition to these settingrelated integrated care initiatives, this survey shows the need to integrate breastfeeding support within the wider healthcare system, including system incentives, which represents an important claim in the light of Kodner's statement, that the structure and performance of integrated healthcare follows funding [2]. However, healthcare systems within industrialized countries currently seem to incentivize routine birth interventions [47] and supplementation with infant formula [48], representing practices known to decrease breastfeeding rates [49]. The lack of healthcare provider time, knowledge and skill in providing breastfeeding support, reported both in this survey and described in the literature as discontinuity of care [50], might be overcome by incentivizing breastfeeding support competence, quality and professional performance within healthcare systems [51].

Incentivizing breastfeeding support within healthcare might also be an adequate measure to counter the poor acknowledgement practitioners reported in this survey. System incentives promoting competence of breastfeeding support might counter educational deficits of healthcare providers. In this respect, respondents emphasized the education of physicians as vital, because of their elevated hierarchic position. Physicians in their role as primary caregivers also have an integrative function within healthcare, since primary care has a central role in integrating care within the healthcare system [52]. Moreover, respondents reported that the poor acknowledgement of breastfeeding support impairs collaboration within healthcare teams. Teamwork is compromised when this lack of recognition exists in combination with inferior work positions and high workload [53]. To facilitate vertically integrated care and integrated care within the maternity care sector, respondents call for implementing higher standards of training into the primary and continuing education of healthcare providers, as also reflected in the literature [54]. Given the WHO recommendation to continue breastfeeding up to two years and beyond [20], it is expected that mother-infant dyads will use various health services over several years from pregnancy to toddlerhood, which makes quality education of all healthcare providers within and beyond maternity healthcare mandatory, to achieve a continuum of care. The IBCLC qualification was generally considered the preferred form of training for those directly involved in maternal/infant healthcare (Table 2), except by respondents from Norway, Sweden, Belgium and Canada, perhaps because they operate in environments where the majority of health professionals receive a high standard of breastfeeding training [55].

The expansion of a milk bank network suggested by respondents, with donor milk recommended by WHO as third choice for infants before formula use [20], might also advance vertically integrated care within breastfeeding support, especially when implemented into national healthcare guidelines [56] and made available by the cooperation of healthcare providers from different care levels. This measure is also apt to reduce industrial influence and infant mortality [57, 58].

In our study, Norway was the exception in many regards, which can be explained given that Norway's breastfeeding support system already fulfills many claims raised by study respondents. This includes adequate maternity leave, providing $80 \%$ of the mother's salary paid for 1 year, as one option to choose for mothers. Further, the nationwide and population-based expansion of the mother support group "Ammehjelpen", developed from La Leche League principles [59], was supported by the Norwegian government, and has contributed, among other factors, to an increase of breastfeeding rates by over 40 \% from 1968 to 1988 [60]. The standard BabyFriendly accreditation of maternity services since the 1990s, combined with ongoing accreditation of neonatology wards and health centers appear to have been adequate to restructure healthcare towards improved integrated breastfeeding support, thus rebuilding their breastfeeding culture over more than four decades [61]. Another factor contributing to this success is the uninterrupted tradition of midwife-led births. With midwives representing the primary caregivers at birth, Norwegian hospitals have met most of the motherfriendly criteria then and now [62]. Moreover, by spreading the Baby-Friendly standard and establishing an agreement with the infant formula industry, Norway has given effect to the International Code of Marketing of 
Breast-milk Substitutes to a degree unmet by many other countries $[63,64]$. Norway has also founded a National Resource Centre for Breastfeeding and a National Advisory Unit functioning as NBC, aimed at advancing breastfeeding protection and promotion, and preventing harmful commercial influence on healthcare, the public and research. Through systematic work to gain political as well as professional support, Norway has achieved and managed to sustain outstanding breastfeeding rates by means of a comprehensive, integrated approach $[49,60,61]$, which is reflected in our study results.

When comparing this achievement with breastfeeding support on an international level, mother support groups rarely meet the high coverage achieved in Norway, currently amounting to about 1:36,000 counsellors per capita [e-mail communication of the first author with Ammehjelpen in October 2015], with the exception of La Leche League groups in New Zealand (about 1:31,000 counsellors per capita), followed by Luxembourg (about 1:37,000 counsellors per capita) and Canada (about 1:68,000 counsellors per capita) [25]. The literature describes the positive impact of mother support groups on breastfeeding rates [30,65], making the promotion of peer support and enhanced collaboration of healthcare providers and volunteers, as suggested by survey participants, appear to be a good investment. For improved integrated care, peer support might also be included in healthcare pathways towards integrated care in breastfeeding support [66].

The worldwide implementation rate of ever designated Baby-Friendly Hospitals amounts to $27.5 \%$, with industrialized countries only scoring $8.5 \%$ [67], showing that other countries fall short of Norwegian standards with $97 \%$ accreditation [e-mail communication of the first author with the Norwegian Resource Center in January 2016]. To obtain a similar growth of breastfeeding rates, other countries with more inhabitants might need an even more comprehensive approach aimed at ingraining integrated care of breastfeeding support within and beyond key settings by using healthcare system incentives $[2,51]$, because the reported major failure of vertically integrated care cannot be resolved by setting-related approaches only.

Both midwives and practitioners in breastfeeding support play a decisive role in facilitating natural maternity processes, which represents common ground in the normative dimension of integrated care [68]. Their collaboration towards concerted action represents an essential component of integrated care in breastfeeding support, in the sense of a continuum of care. In this survey practitioners in breastfeeding support in addition to midwives describe an unsatisfactory integration of their profession into regular healthcare, which is reflected in current developments [69] and counter-strategies facilitating more natural births [70, 71]. In this respect, survey participants suggest that health insurance companies should take on the responsibility to incentivize natural birth and breastfeeding. towards sustainability of maternity healthcare, and on the other hand control and restrict over-medication and unnecessary interventions at birth [72-74], which reduce birthing choices for parents [47] and thus represent unfavorable routines for breastfeeding initiation [33, 62].

According to respondents, for parents, a shared decision on infant feeding is hindered by discontinuity of care, caused by healthcare providers poorly educated in breastfeeding support, inconsistent advice and poor societal support $[50,75,76]$. As a result, parents lack relevant facts for shared decision-making, and the practical how-to for successful breastfeeding enabling them to reach individual breastfeeding goals [77]. There are many examples from industrialized countries, where breastfeeding is initiated by between $70 \%$ and $90 \%$ of mothers, but breastfeeding rates drop rapidly within a few weeks $[78,79]$. This indicates the intention of parents to breastfeed on one hand, and the failure of breastfeeding support on the other hand, thus reducing infant feeding choices for parents [31, 80]. The lack of consistency and continuity of care represents a decisive factor for discontinuation of breastfeeding, while the resource of peer support as social capital often remains unused $[65,66]$. Access to competent breastfeeding support might even be more difficult for parents with lower socioeconomic status, potentially increasing health inequalities [81-85].

The overwhelming consensus of international practitioners in breastfeeding support is the lack of breastfeeding health promotion strategies, reflecting the halfheartedness of current policies on infant feeding in industrialized countries [86]. The most vulnerable population groups are often subject to formula industry marketing strategies, unhindered by governments or even with their support [87], as illustrated by the former version of the US Women, Infant and Children program [88] and the current lobbyist activities in Canada [89]. Ineffective policies can cause more damage than no policies, because they prevent progress by pretending that measures have already been taken [86]. According to the results of this survey, building political consensus and a follow-up of health promotion strategies is essential to effectively implement integrated care within breastfeeding support.

As reports from different countries show, National Breastfeeding Committees may noticeably impact breastfeeding rates, an important health outcome, when empowered and supported by their governments to take on the National leadership in breastfeeding protection, promotion and support [90-92]. This includes spreading the BabyFriendly Initiative and constructing policies effectively to fulfill their original tasks [16]. According to respondents, 
only about half of the existing policies to protect and promote breastfeeding within this sample work efficiently and make an impact. NBCs lack funds, power and influence. This shortcoming of policies might be due to industrial influence and their non-transparent strategies [86-89], and a lack of Code implementation $[19,57]$, preventing progress towards integrated breastfeeding support.

In our study, respondents saw National Breastfeeding Committees playing a key role in breastfeeding protection and promotion as a delivery system, calling upon governments to create this institution and provide financial support for the many varied and important functions of this authoritative body. The newly defined tasks of the National Breastfeeding Committee by respondents may assist governments in establishing integrated care in breastfeeding support, steering towards breastfeeding-friendliness of society and cost-efficiency, prevention and sustainability within healthcare [93, 94]. Valentijn et al. [68] describe normative and functional integration at three levels of healthcare: micro (clinical), meso (healthcare professional and organizational) and macro (system) integration. In terms of breastfeeding support this means that the NBC should ensure normative integration towards breastfeedingfriendliness within and beyond healthcare, providing seamless connectivity across all three levels in the sense of functional integration. Thus the NBC faces a complex challenge in promoting society-wide support for breastfeeding.

The task for all healthcare systems to overcome unfavorable routines, structures, legislation and quality gaps $[17,18,30,31,62,74,77,78,95]$; and develop towards integrated care in breastfeeding support and sustainablity, implies a long-lasting process. Even with active support from the government, Norway took several decades to establish improved quality of breastfeeding support within healthcare and society as an ongoing process, including the current accreditation of communities as Baby-Friendly. On the other hand, the half-hearted policies and reduction of midwifery services in Germany, contribute to the disintegration of breastfeeding support $[69,86]$, indicating that on a global level there is not only progress, but also regression of integrated care in breastfeeding support. This backlash and slow progress is reflected in the overdue implementation, since the 1980s, of international public health nutrition policy initiatives [13-20]. Against this background, this study represents a highly topical approach to establish healthcare systems that are geared to providing integrated care to support breastfeeding mothers.

\section{Strengths and limitations}

Even though participants in this study represent a convenience sample of self-selected practitioners in breastfeeding support, the majority were from high income
European countries, their knowledge about the obstacles to integrated breastfeeding support, which they experience in their everyday work environment, is considerable and worth noting.

This survey investigates for the first time the opinions of international practitioners in breastfeeding support, and puts integrated care in breastfeeding support in perspective. Respondents described aspects of integrated care within many different healthcare settings, covering a broad spectrum of topics, enabling us to provide a comprehensive overview of its relevant components. Moreover, an evaluation of National Breastfeeding Committees' performance, from practitioners' perspective, including their expectations, has not been explored, either. Agreement of opinions among international participants, e.g. on the major importance of integrated care and health policies to facilitate effective breastfeeding support, gives additional strength to the findings. These might be useful for policy makers to further breastfeeding protection, promotion and support on a national or global level. Further research might focus on the implementation of these suggested measures and policies, and on the evaluation of their results in terms of breastfeeding rates.

\section{Conclusions}

The task of providing integrated care in breastfeeding support to facilitate breastfeeding initiation and sustainment is a challenging one, requiring a re-structuring of the healthcare system. The new structure would involve integrating lactation consulting as a profession, educating all healthcare professionals in breastfeeding support, creating system incentives for natural birth and breastfeeding, and implementing quality standards in key healthcare settings, such as the Mother- and BabyFriendly accreditation. A continuum of care, involving the cooperation of competent healthcare providers, is vital for families to experience shared decision-making regarding infant feeding and the how-to of successful breastfeeding, independent of their socioeconomic background. This comprehensive task cannot be accomplished successfully without strong political consensus and a clear health policy to protect, promote and support breastfeeding as a sustainable resource of public health, which might be coordinated by an empowered National Breastfeeding Committee.

\section{Additional files}

Additional file 1: The failure of vertical integration of breastfeeding support, according to the categorization of open-ended responses. (DOCX 25 kb)

Additional file 2: The failure of health promotion strategies, including suggestions for improvement, according to the categorization of openended responses. (DOCX $24 \mathrm{~kb}$ ) 


\section{Abbreviations}

ABA: Australian Breastfeeding Association; ABM: Academy of Breastfeeding Medicine; AFS: Arbeitsgemeinschaft Freier Stillgruppen [Work group of free breastfeeding support groups], represented in Germany and Austria; BFCl: Baby-Friendly Community Initiative; BFHI: Baby-Friendly Hospital Initiative; Code: International Code of Marketing of Breast-Milk Substitutes; ELACTA: European Lactation Consultants Alliance; FABM: Fellow of the Academy of Breastfeeding Medicine; IBCLC: International Board Certified Lactation Consultant; IBFAN: International Baby Food Action Network; ILCA: International Lactation Consultant Association; LC: Lactation Consultant; LLL: La Leche League; MFHI: Mother-Friendly Hospital Initiative; NBC: National Breastfeeding Committee; UNICEF: United Nations International Children's Emergency Fund; VELB: Verband Europäischer Lakationsberaterlnnen [Association of European Lactation Consultants]; WHO: World Health Organization; WIC: Women, Infants, and Children (US Supplemental Nutrition Program).

\section{Acknowledgements}

We thank the practitioners in breastfeeding support who participated in this study. We thank the organizers of the breastfeeding conferences La Leche League Germany, European Lactation Consultants Alliance, International Lactation Consultant Association and Academy of Breastfeeding Medicine for permission to conduct the study at their international conferences. We thank the PhD course team of Bielefeld University in Germany for their support. We thank the Medical Faculty of Split, Croatia, including the TRIBE PhD course team, for their support.

We thank Cornelia Züll, qualitative methods department, Michael Wiedenbeck, quantitative methods department and Rolf Porst, questionnaire expert, from the GESIS Leibniz Institute Mannheim, Germany, for their feedback supplied on questionnaire development, data evaluation and interpretation. We thank Adriano Cattaneo and his research team in Trieste, Italy, for their consistent support including bivariate evaluations, data interpretation and revisions. We thank Christine Bruni-Volz for her support including the final translation check of open-ended responses.

We thank Fiona Dykes for her feedback on the evaluation of open-ended responses and her contribution to the creation of the thematic networks National Breastfeeding Committee figure.

We thank James Akre for his feedback on the wording of several paragraphs and the thematic networks National Breastfeeding Committee figure. We thank the Norwegian Resource Centre for Breastfeeding, especially Gro Nylander, and the founder of Ammehjelpen Elisabet Helsing, for their support and feedback.

We thank Lydia de Raad for her proofread and feedback regarding all LLLI-related aspects including minor revisions.

No funding was received for this study.

\section{Authors' contributions}

SR conducted the study within a PhD course in health sciences at Bielefeld University. SR translated, evaluated and interpreted the data in teamwork with the co-author and others (see acknowledgements), developed the manuscript draft and conducted revisions in cooperation with the co-author. IZ-G was involved in data interpretation and conducted critical reviewing of the manuscript. All authors read and approved the final manuscript.

\section{Competing interests}

The authors declare that they have no competing interests.

\section{Author details}

${ }^{1}$ www.stillberatung-rosin.de, Berlin, Germany. ${ }^{2}$ School of Medicine, University of Split, Split, Croatia.

\section{Received: 1 September 2015 Accepted: 9 May 2016}

\section{Published online: 03 June 2016}

\section{References}

1. World Health Organization. Integrated Health Services - What and why? Technical Brief No.1, 2008. https://www.google.de/ url? sa $=$ t\&rct=j\&q=\&esrc $=s \&$ source $=$ web\&cd $=1 \&$ ved $=0$ ahUKEwic_KrX3 fKAhWKJZoKHSIzAmlQFgghMAA\&url=http\%3A\%2F\%2Fwww.who.int\% 2Fhealthsystems\%2Fservice_delivery_techbrief1.pdf\&usg=AFQjCNGgrExiKNfle1 p3ET9q1_D2QTfvKg\&bvm=bv.114195076,d.bGs\&cad=rja. Accessed 12 May 2016.
2. Kodner DL, Spreeuwenberg C. Integrated care: meaning, logic, applications, and implications-a discussion paper. Int J Integr Care. 2002;2:e12.

3. The prevalence and duration of breastfeeding: a critical review of available information. World Health Stat Q. 1982:35:92-116.

4. Wolf JH. Low breastfeeding rates and public health in the United States. Am J Public Health. 2003:93(12):2000-10.

5. Apple RD. The medicalization of infant feeding in the United States and New Zealand: two countries, one experience. J Hum Lact. 1994;10(1):31-7.

6. Acta Paediatrica Special Issue. Impact of Breastfeeding on Maternal and Child Health. Acta Paediatr. 2015;104(S467):1-134.

7. Renfrew MJ, Pokhrel S, Quigley M, McCormick F, Fox-Rushby J, Dodds R, et al. Preventing disease and saving resources. London: UNICEF UK; 2012.

8. Ip S, Chung M, Raman G, Chew P, Magula N, DeVine D, et al. Breastfeeding and maternal and infant health outcomes in developed countries. Evid Rep Technol Assess. 2007:153:1-186.

9. Jones G, Steketee RW, Black RE, Bhutta ZA, Morris SS. How many child deaths can we prevent this year? Lancet. 2003;362(9377):65-71.

10. Bartick M, Reinhold A. The burden of suboptimal breastfeeding in the United States: A pediatric cost analysis. Pediatrics. 2010;125(5):e1048-56.

11. Smith J, Harvey P. Chronic disease and infant nutrition: is it significant to public health? Public Health Nutr. 2011;14(2):279-89.

12. Avery A, Zimmermann K, Underwood PW, Magnus JH. Confident commitment is a key factor for sustained breastfeeding. Birth. 2009:36(2):141-8.

13. United Nations International Children's Emergency Fund (UNICEF) UK. The Baby-Friendly Initiative. 2010. http://www.unicef.org.uk/BabyFriendly/AboutBaby-Friendly/. Accessed 12 May 2016.

14. United Nations International Children's Emergency Fund (UNICEF). The Baby-Friendly Hospital Initiative. 2005. http://www.unicef.org/nutrition/ index_24806.html. Accessed 12 May 2016.

15. Macaluso A, Bettinelli ME, Chapin EM. Córdova do Espírito Santo L, Mascheroni $\mathrm{R}$, Murante AM, et al. A controlled study on Baby-Friendly Communities in Italy: methods and baseline data. Breastfeed Med. 2013:8(2):198-204.

16. World Health Organization/United Nations International Children's Emergency Fund. Innocenti Declaration on the protection, promotion and support of breastfeeding. Florence. 1990; 2005.

17. World Breastfeeding Trends Initiative. http://worldbreastfeedingtrends.org/ country-report-wbti/. Accessed 12 May 2016.

18. IBFAN - International Baby Food Action Network, Committee on the elimination of discrimination against women, report on the situation of infant and maternal health and work-related issues. http://ibfan.org/cedaw. Accessed 12 May 2016.

19. World Health Organization. International Code of Marketing of Breast-milk Substitutes. 1981. www.who.int/nutrition/publications/code_english.pdf. Accessed 12 May 2016.

20. World Health Organization, United Nations International Children's Emergency Fund. Global strategy for infant and young child feeding. Geneva: WHO Library Cataloguing-in-Publication Data; 2003.

21. Pound MC, Williams K, Grenon R, Aglipay M, Plint AC. Breastfeeding Knowledge, Confidence, Beliefs, and Attitudes of Canadian Physicians. J Hum Lact. 2014;30(3):298-309.

22. Boyd AE, Spatz DL. Breastfeeding and Human Lactation: Education and Curricular Issues for Pediatric Nurse Practitioners. J Pediatr Health Care. 2013; 27:83-90.

23. Renfrew MJ, McFadden A, Dykes F, Wallace LM, Abbott S, Burt S, Anderson JK. Addressing the learning deficit in breastfeeding: strategies for change. Matern Child Nutr. 2006;2(4):239-44.

24. Wallace LM, Kosmala-Anderson J. Training needs survey of midwives, health visitors and voluntary-sector breastfeeding support staff in England. Matern Child Nutr. 2007;3(1):25-39.

25. La Leche League International. 2014. www.lalecheleague.org. Accessed 12 May 2016.

26. Australian Breastfeeding Association, https://www.breastfeeding.asn.au/. Accessed 12 May 2016.

27. Arbeitsgemeinschaft Freier Stillgruppen [Work group of free breastfeeding support groups], http://www.afs-stillen.de. Accessed 12 May 2016.

28. International Lactation Consultant Association. Position Paper on the Role and Impact of the IBCLC. 2011, http://www.ilca.org/files/resources/ilca publications/Role\%20\%20lmpact\%20of\%20the\%20IBCLC-webFINAL_08-15-11.pdf. Accessed 12 May 2016

29. Academy of Breastfeeding Medicine. 2014, http://www.bfmed.org/. Accessed 12 May 2016. 
30. Hannula L, Kaunonen M, Tarkka MT. A systematic review of professional support interventions for breastfeeding. J Clin Nurs. 2008;17:1132-43.

31. Renfrew MJ, McCormick FM, Wade A, Quinn B, Dowswell T. Support for healthy breastfeeding mothers with healthy term babies. Cochrane Database Syst Rev. 2012;16:5.

32. Chin LY, Amir LH. Survey of patient satisfaction with the Breastfeeding Education and Support Services of The Royal Women's Hospital, Melbourne. BMC Health Serv Res. 2008;8:83.

33. Odent M. Birth and Breastfeeding: Rediscovering the Needs of Women during Pregnancy and Childbirth. Russet, United Kingdom: Clairview Books; 2003.

34. Law SM, Dunn OM, Wallace LM, Inch SA. Breastfeeding Best Start study: training midwives in a 'hands off' positioning and attachment intervention. Matern Child Nutr. 2007;3(3):194-205.

35. International Journal of Integrated Care, Focus and Scope. http://www.ijic. org/about/. Accessed 12 May 2016

36. Porst R. Fragebogen. Ein Arbeitsbuch. [Questionnaire. A work book.]. Wiesbaden: VS Verlag für Sozialwissenschaften GWV Fachverlage GmbH; 2008.

37. Pope C, Ziebland S, Mays N. Qualitative research in health care. Analysing qualitative data. BMJ. 2000;320(7227):114-6.

38. McColl E, Jacoby A, Thomas L, Soutter J, Bamford C, Steen N, et al. Design and use of questionnaires: a review of best practice applicable to surveys of health service staff and patients. Health Technol Assess. 2001;5(31):1-256.

39. O'Cathain A, Thomas K. "Any other comments?" Open questions on questionnaires - a bane or a bonus to research? BMC Med Res Methodol. 2004; $4: 25$.

40. Rosin S. Assessing the international situation of breastfeeding, lactation consulting and breastfeeding promotion as viewed by international, interdisciplinary experts and resulting recommendations, http://pub.unibielefeld.de/publication/2663500. Accessed 12 May 2016.

41. Krippendorff K. Content Analysis. 3rd ed. Los Angeles: Sage Publications Ltd; 2012.

42. Attride-Stirling J. Thematic networks: an analytic tool for qualitative research. Qual Res. 2001;1(3):385-405.

43. Zakarija-Grkovic I, Burmaz T. Effectiveness of the UNICEF/WHO 20-hour course in improving health professionals' knowledge, practices, and attitudes to breastfeeding: before/after study of 5 maternity facilities in Croatia. Croat Med J. 2010:51(5):396-405.

44. Lukac M, Riley JK, Humphrey AD. How to integrate a lactation consultant in an outpatient clinic environment. J Hum Lact. 2006;22(1):99-103.

45. Sinha B, Chowdhury R, Sankar MJ, Martines J, Taneja S, Mazumder S, et al. Interventions to improve breastfeeding outcomes: a systematic review and meta-analysis. Acta Paediatr. 2015;104:114-34.

46. Vari PM, Camburn J, Henly SJ. Professionally mediated peer support and early breastfeeding success. J Perinat Educ. 2000;9(1):22-30.

47. World Health Organization. Technical Working Group: Care in normal birth: a practical guide. Birth. 1997;24(2):121-3.

48. Becker GE, Remmington S, Remmington T. Early additional food and fluids for healthy breastfed full-term infants. Cochrane Database Syst Rev. 2011:12: CD006462.

49. Häggkvist A, Brantsæter A, Grjibovski A, Helsing E, Meltzer H, Haugen M. Prevalence of breast-feeding in the Norwegian Mother and Child Cohort Study and health service-related correlates of cessation of full breastfeeding. Public Health Nutr. 2010;13(12):2076-86.

50. Garner CD, Ratcliff SL, Thornburg LL, Wethington E, Howard CR, Rasmussen KM. Discontinuity of breastfeeding care: "There's no captain of the ship". Breastfeed Med. 2016;11:32-9.

51. Christianson J, Leatherman S, Sutherland K. Financial Incentives, Healthcare Providers and Quality Improvements. A Review of the Evidence. London: The Health Foundation; 2007.

52. Valentijn PP, Schepman SM, Opheij W, Bruijnzeels MA. Understanding integrated care: a comprehensive conceptual framework based on the integrative functions of primary care. Int J Integr Care. 2013;13:e010.

53. Brown J, Lewis L, Ellis K, Stewart M, Freeman TR, Kasperski MJ. Conflict on interprofessional primary health care teams - can it be resolved? J Interprof Care. 2011;25(1):4-10.

54. United States Breastfeeding Committee. Core Competencies in Breastfeeding Care and Services for All Health Professionals. 2015, http://www.usbreastfeeding.org/p/cm/ld/fid=170. Accessed 12 May 2016.
55. Ekstrom A, Kylberg E, Nissen E. A process-oriented breastfeeding training program for healthcare professionals to promote breastfeeding: an intervention study. Breastfeed Med. 2012;7(2):85-92.

56. Arnold L. Global health policies that support the use of banked donor human milk: a human rights issue. Int Breastfeed J. 2006;1:26.

57. Rollins NC, Bhandari N, Hajeebhoy N, Horton S, et al. Why invest, and what it will take to improve breastfeeding practices? Lancet. 2016;387(10017):491-504.

58. Arslanoglu S, Moro GE, Bellù R, Turoli D, De Nisi G, Tonetto P, Bertino EJ. Presence of human milk bank is associated with elevated rate of exclusive breastfeeding in VLBW infants. Perinat Med. 2013;41(2):129-31.

59. Ammehjelpen. [Norwegian breastfeeding support group], https:// ammehjelpen.no/helpers-in-english. Accessed 12 May 2016.

60. Liestø| K, Rosenberg M, Walløe L. Breast-feeding practice in Norway 1858-1998. J Biosoc Sci. 1988;20:45-58.

61. Hansen MN, Bærug A, Nylander G, Häggkvist A-P, Tufte E, Alquist R, et al. Challenges and Successes: The Baby-Friendly Initiative in Norway. J Hum Lact. 2012;28(3):285-8.

62. Lothian JA. Introduction: the coalition for improving maternity services. J Perinat Educ. 2007:16 Suppl 1:1S-4.

63. An International Comparison Study into the implementation of the WHO Code and other breastfeeding initiatives, http://www.health.gov.au/internet/main/ publishing.nsf/Content/int-comp-whocode-bf-init. Accessed 12 May 2016.

64. The International Baby Food Action Network, http://www.ibfan.org. Accessed 12 May 2016.

65. Kaunonen M, Hannula L, Tarkka MT. A systematic review of peer support interventions for breastfeeding. J Clin Nurs. 2012;21(13-14):1943-54.

66. Thomson G, Balaam M-C, Hymers K. Building social capital through breastfeeding peer support: insights from an evaluation of a voluntary breastfeeding peer support service in North-West England. Int Breastfeed J. 2015;10:15.

67. Labbok MH. Global baby-friendly hospital initiative monitoring data: update and discussion. Breastfeed Med. 2012;7:210-22.

68. Valentijn PP, Boesveld IC, van der Klauw DM, Ruwaard D, Struijs JN, Johanna JW, Molema JW, Bruijnzeels MA, Vrijhoef HJM. Towards a taxonomy for integrated care: a mixed-methods study. Int J Integr Care. 2015;15:e003.

69. Butterfly Beginnings: The end of German midwifery as we know it? Posted on October 21, 2015. https://www.bb-doula.com/blog/birth_rights/the-endof-german-midwifery-as-we-know-it/. Accessed 12 May 2016.

70. Royal College of Obstetricians and Gynaecologists. Maternity Services Pathway: A Simple Guide 2012/13. London; 2012/2013.

71. NICE guidelines [CG190], 2014. http://www.nice.org.uk/guidance/cg190/ chapter/key-priorities-for-implementation. Accessed 12 May 2016.

72. Sandall J, Soltani H, Gates S, Shennan A, Devane D. Midwife-led continuity models versus other models of care for childbearing women. Cochrane Database Syst Rev. 2013;8:CD004667.

73. Conrad P, Mackie T, Mehrotra A. Estimating the costs of medicalization. Soc Sci Med. 2010;70(12):1943-7.

74. Renfrew MJ, McFadden A, Bastos MH, Campbell J, Channon AA, Cheung NF, et al. Midwifery and quality care: findings from a new evidence-informed framework for maternal and newborn care. Lancet. 2014;384(9948):1129-45.

75. Health \& Social Care Information Centre. Infant Feeding Survey - UK. 2010, http://www.hscic.gov.uk/article/2021/Website-

Search?productid $=9569 \&$ q=infant+feeding +survey\&sort=Relevance\&size=10\&page=1\&area=both\#top. Accessed 12 May 2016.

76. McKinnon LC, Prosser SJ, Miller YD. What women want: qualitative analysis of consumer evaluations of maternity care in Queensland, Australia. BMC Pregnancy Childbirth. 2014;14:366.

77. Odom EC, Li R, Scanlon KS, Perrine CG, Grummer-Strawn L. Reasons for earlier than desired cessation of breastfeeding. Pediatrics. 2013;131(3):e726-32.

78. Centers for Disease Control and Prevention. Breastfeeding Report Card United States. 2012, www.cdc.gov/breastfeeding/data/reportcard2.htm. Accessed 12 May 2016.

79. Cattaneo A, Burmaz T, Arendt M, Nilsson I, Mikiel-Kostyra K, Kondrate I, et al. Protection, promotion and support of breast-feeding in Europe: progress from 2002 to 2007. Public Health Nutr. 2010;13(6):751-9.

80. Coates R, Ayers S, de Visser R. Women's experiences of postnatal distress: a qualitative study. BMC Pregnancy Childbirth. 2014;14:359.

81. Higginbottom GM, Morgan M, Alexandre M, Chiu Y, Forgeron J, Kocay D, et al. Immigrant women's experiences of maternity-care services in Canada: a systematic review using a narrative synthesis. Syst Rev. 2015;4:13. 
82. Loignon C, Hudon C, Goulet É, Boyer S, De Laat M, Fournier N, et al. Perceived barriers to healthcare for persons living in poverty in Quebec, Canada: the EQUIhealThY project. Int J Equity Health. 2015;14:4.

83. Amir LH, Donath SM. Socioeconomic status and rates of breastfeeding in Australia: evidence from three recent national health surveys. Med I Aust. 2008;189(5):254-6.

84. Flacking R, Nyqvist KH, Ewald U. Effects of socioeconomic status on breastfeeding duration in mothers of preterm and term infants. Eur J Public Health. 2007;17(6):579-84.

85. Heck KE, Braveman P, Cubbin C, Chavez GF, Kiely JL. Socioeconomic status and breastfeeding initiation among California mothers. Public Health Reports. 2006;121(1):51-9.

86. Rouw E, Hormann E, Scherbaum V. The high cost of half-hearted breastfeeding promotion in Germany. Int Breastfeed J. 2015;9:22.

87. Palmer G. The Politics of Breastfeeding: When Breasts are bad for Business. 3rd ed. London: Pinter \& Martin; 2009.

88. Tuttle CR, Dewey KG. Potential cost savings for Medi-Cal, AFDC, food stamps, and WIC programs associated with increasing breast-feeding among low-income Hmong women in California. J Am Diet Assoc. 1996; 96(9):885-90.

89. Infant Feeding Action Coalition Canada. Nestlé has teamed up with Food Banks, targeting low income mothers with free formula, http://infactcanada. ca/food-banks-canada-nestle-letter.html. Accessed 12 May 2016

90. Hofvander Y. Breastfeeding and the Baby Friendly Hospitals Initiative (BFHI): organization, response and outcome in Sweden and other countries. Acta Paediatr. 2005;94(8):1012-6.

91. Olang B, Farivar K, Heidarzadeh A, Strandvik B, Yngve A. Breastfeeding in Iran: prevalence, duration and current recommendations. Int Breastfeed J. 2009:4:8.

92. Rea MF. A review of breastfeeding in Brazil and how the country has reached ten months' breastfeeding duration. Cadernos de saude publica/ Ministerio da Saude, Fundacao Oswaldo Cruz, Escola Nacional de Saude Publica. 2003;19 Suppl 1:S37-45.

93. Victora CG, Bahl R, Barros AJD, França GVA, et al. Breastfeeding in the 21st century: epidemiology, mechanisms, and lifelong effect. Lancet. 2016; 387(10017):475-90.

94. Hansen K. Breastfeeding: a smart investment in people and in economies. The Lancet. 2016;387(10017):416.

95. Lawrence RA, Howard CR. Progress and challenges from the seventh summit on breastfeeding. Breastfeed Med. 2015;10(8):383-4.

\section{Submit your next manuscript to BioMed Central and we will help you at every step:}

- We accept pre-submission inquiries

- Our selector tool helps you to find the most relevant journal

- We provide round the clock customer support

- Convenient online submission

- Thorough peer review

- Inclusion in PubMed and all major indexing services

- Maximum visibility for your research

Submit your manuscript at www.biomedcentral.com/submit

C Biomed Central 